\title{
1. Towards radical subjects: workplace spirituality as neoliberal governance in American business
}

\author{
James Dennis LoRusso
}

There is only one social responsibility of business - to use its resources and engage in activities designed to increase its profits so long as it stays within the rules of the game, which is to say, engages in open and free competition without deception or fraud. (Milton Friedman, New York Times Magazine, September 1970)

In these words written nearly 50 years ago, Milton Friedman, the Nobel Laureate economist and father of the Chicago School of economics, expressed the prevailing view of American business at mid-century: that business exists solely for the pursuit of profits. Anything else is superfluous. Surely, the notion that companies should devote any of their energies towards other ends would have seemed foreign, perhaps even nonsensical. The truism, often attributed to long-time chief executive officer (CEO) of General Motors Alfred P. Sloan, that 'the business of business is business,' certainly still rang true. Yet today, the culture of business couldn't appear more different. Companies, at least on their public face, more often present themselves as responsible stewards of society, boasting aspiration mission statements, entire divisions devoted to 'corporate social responsibility,' and core values committed to respecting the dignity of their employees. Every year since 1998, Fortune magazine publishes its coveted list of the 'Best Companies to Work For,' measured not by their profit margins but how they ensure a fulfilling and rewarding experience for their workforces.

The expectation that work should be 'more than a paycheck' but also intrinsically rewards seems almost unexceptional to working people today. The workplace of the twenty-first century aims to be a space to which individuals can bring their 'whole selves.' Business schools and corporate training programs instill ideas about management and 'leadership' as a form of service to others, specifically for their clientele and their staff. Indeed, for a growing number of firms, business leaders, and even mid-level managers, this quest has taken on 'spiritual' significance. Companies offer extracurricular courses that claim to draw on spiritual disciplines in order to promote employee well- 
being. Google, for example, introduced a two-day workshop called 'Search Inside Yourself,' that instructs employees in meditation techniques that will presumably help them avoid burnout and achieve better 'work-life balance' (Lebowitz 2016).

Scholars in the business world and the humanities have dubbed this latter trend to introduce various spiritual perspectives into their organizations, 'workplace spirituality.' Religion scholar Lake Lambert III understands workplace spirituality as 'important religious movement shaping and being shaped by American business culture' (Lambert III 2009, p. 18). Others offer a more critical assessment of this development. Sociologist Douglas Hicks (2003) worries that these efforts risk becoming 'religions of the workplace,' corporate cultures that use spiritual perspectives to elicit increased productivity and profit margins.

The vast majority of research into workplace spirituality overwhelmingly stems from scholars in the business world, where professional interests in understanding effective management strategies blur the line between disinterested scholarship and overt advocacy. In fact, American scholars of management, beginning in the mid-1990s, were among the first to articulate and identify this trend in the business world, and in fact, it was they who first coined the term 'workplace spirituality.' Too often, however, the study of workplace spirituality has tilted towards outright advocacy, envisioning the trend as a positive development for business and working people alike, while ignoring its broader implications for society.

The purpose of this chapter is to begin to highlight the power dynamics of this trend, to provide some measure of historical context, and to ponder the way in which workplace spirituality exacerbates existing forms of socioeconomic imbalances. Eschewing conventional qualitative and quantitative methods that dominate the field of management, this chapter privileges critical approaches offered by social theorists, indicative of the work of cultural historians, discourse analysis, and practice theories. The basic claim of this chapter is that workplace spirituality, contrary to the claims of most management scholars, represents a distinctly neoliberal form of managerial control. Rather than a radical departure from conventional management thought and practice, it is an extension of existing strategies that reproduce the very conditions from which they purport to liberate and improve the lives of working people. Workplace spirituality not only functions as an effective tool for management, it represents what Michel Foucault calls a 'technology of the self,' engendering new forms of subjectivity suited to the conditions of twenty-first-century work. In short, when spirituality becomes part of the fabric of a workplace culture, individuals adopt interpretive strategies and enact practices that render them, perhaps unwittingly, participants in their own subordination to the interests of management and to a broader neoliberal status quo. After establishing the 
conceptual relationships between neoliberalism, workplace spirituality, and subjectivity, the chapter will examine how these elements intersect with two domains of American business. First, I explore how workplace spirituality reinforces neoliberalization in management education. Second, the chapter draws on ethnographic fieldwork conducted at a coffee shop chain located in the western United States that has explicitly adopted 'spiritual' discourses as a central component of organizational culture. Each of these cases illustrates how spiritual regimens operate to recast individuals as neoliberal subjects suited to their particular location, whether frontline workers or business professionals, within the class structure of American society. In this way, we can begin to see how spiritual discourses participate in much broader cultural processes that uphold neoliberal capitalism.

\section{WORKPLACE SPIRITUALITY AS NEOLIBERAL SUBJECT FORMATION}

\section{Conceptualizing Neoliberalism}

Neoliberalism is a concept that defies simple explanation. Perhaps more prevalent in European than North American public discourse, it has been defined variously and inconsistently, and therefore I can only hope to offer some precision in how I will conceptualize this term herein. David Harvey, whose grasp of this elusive concept surpasses most, suggests that neoliberalism is a theory of political economy, grounded in the belief that human wellbeing is best secured by promoting free trade, free markets, and a strong defense of private property rights. He characterizes it as hegemonic, as the 'common sense' of today (Harvey 2005, pp. 2-3).

I agree with Harvey's assessment that what he labels neoliberalism is the normalized way of understanding the world, especially in the capitalist West, yet his depiction remains inadequate. Because Harvey presents neoliberalism as a ruling ideology, his conceptualization obscures the myriad contested and dynamic social processes that often fall under its banner. The wide array of factors that converge in the concept cannot be reduced to Harvey's portrait of neoliberalism as a set of coherent, interconnected, and largely stable set of principles that give rise to a consistent assortment of formal policies. Rather, as Jamie Peck argues, we must attend to the inherently unstable quality of neoliberalization, which 'does not follow the pristine path of rolling market liberalization and competitive convergence; it is one of repeated, prosaic, and often botched efforts to fix markets, to build quasi-markets, and to repair market failures' (Peck 2010, p. xiii). Peck does characterize neoliberalism as a discursive formation, but he frames it primarily as a practical discourse strategically mobilized to uphold the ideological purity of capitalist markets, 
rather than an ideology in and of itself. Whereas Harvey asserts neoliberalism as a political project to restore class power (2005, p. 16), Peck takes us further. It is not only fueled by a resistance to the welfare state or working-class power, but by the failure of really-existing-capitalism to live up to the utopian promises of its most fervent adherents.

Marnie Holborow likewise recognizes this slippage between 'what neoliberalism says and what it does' $(2015$, p. 9). While proponents of free markets decry government interference with supply and demand, they actively utilize the state to create, sustain, and shape markets in order to defend the interests of capital. The chasm between, on one hand, capitalist ideologies, and the policies its advocates support, on the other hand, defines neoliberalism. Ideologies justify the practice, and in turn, the practices legitimize the ideology, all of which renders the social contradictions inevitable.

The sense that somehow the conditions produced by capitalism are inevitable and a reflection of the natural order is crucial to understanding neoliberalism as a dynamic cultural phenomenon. Rather than a set of standard orthodoxies, as Harvey suggests, neoliberalism resides beneath the mantle of overt discourse, what Pierre Bourdieu refers to as doxa, a set of subjective principles that, in the quotidian world, lie beyond even the possibility of critique because they are experienced as self-evident, irreducible, objective conditions of the natural world (Bourdieu [1972] 1977, p. 164). It is literally a crucial element of the discursive air we breathe, woven into the collective cultural fabric in which individuals in capitalist societies become 'human.' Thus, it is here, at the level of human subject formation that I hope to illuminate the way that neoliberalism nonetheless persists and even thrives through attempts to overcome its most pernicious effects. Conceptualizing neoliberalism in this manner draws it out of hiding, transforming it from a doxa beyond recognition to a set of historically situated orthodoxies capable of critique. We will be able to see that human beings are not naturally or inevitably entrepreneurial. They are made that way through neoliberal disciplinary regimes.

If a critique of neoliberalism attempts to denaturalize what is typically taken for granted, to rehistoricize that which is commonly framed as sui generis, and to repoliticize that which otherwise has persisted as descriptive empirically rather than prescriptive ideologically, then I propose that neoliberal spiritualities, including workplace spirituality, operate at an inverse trajectory. They further mystify the logic and institutions of capitalism as more than natural, indeed, supernatural, as not merely ahistorical but a keystone of some cosmic order. Neoliberal forms of spirituality are not merely the way the world is but the perfected, if unattainable, telos of human existence. I want to suggest that workplace spirituality, as articulated by its champions, performs this precise ideological work. 


\section{Workplace Spirituality as Neoliberal Project}

On its face, workplace spirituality is, as advocates suggest, a way of fulfilling an employer's obligation to care for both the material and immaterial needs of its employees. They see it as a part of a long-term effort to improve the quality of work, a remedy for traditional patterns of management practice, which tended to treat workers as simply one more factor of production. Not only should companies provide for the livelihood of their employees, they should actively promote their overall wellbeing, which includes spiritual health. Organizations have pursued this end in numerous ways. Some firms, like Google, Nike, and Salesforce, have embraced this practice, carving out physical spaces where individuals may 'recharge' through relaxation, meditation, or engage in daily prayers (Garvey 2018). Others allow their employees to form affinity groups, or 'employee resource groups,' that bring together staff, typically under the watchful eye of human resource departments who share a particular religious identity. ${ }^{2}$ Faith-based and interfaith employee groups treat workplace spirituality as an extension of diversity and inclusion with religion as an important marker or identity in need of formal recognition and respect from the employer. Still others, like Tyson Foods, provide corporate chaplains, trained professionals ready and willing to serve as counsel for individuals of any faith background. ${ }^{3}$ Some businesses directly articulate their organizational culture or corporate mission in explicitly spiritual or religious terms.

Researchers from the study of management and other disciplines consider each of these examples as comprising a broader trend within American business in recent decades to attend to the spiritual needs of working people. David Miller, the director of the Faith and Work initiative, argues that the 'Faith at Work movement' represents a response to various social, economic, and cultural factors that came to a head during the late 1980s and early 1990s. Miller (2007) claims that religious institutions (namely the Church) have failed to equip their members to adequately deal with the anxieties brought about by the effects of globalization, corporate downsizing, and the diminishing prospect of lifelong employment. Consequently, laypeople have formed their own voluntary associations that draw on religious resources for sustenance. Management scholar Judi Neal, a long-time advocate for workplace spirituality, also attributes the rising business interest in spirituality to broad global socioeconomic trends. Yet, while Miller decries the absence of a robust theology of work on the part of churches, Neal (2006) explains rising corporate interest in spirituality as the result of a tectonic 'spiritual awakening' originating in the counterculture of the 1960s and early 1970s. While other scholars offer various explanations, they generally concede that workplace spirituality represents a movement to reform the culture of business in ways that empower working people to be their 'whole selves' on the job. ${ }^{4}$ 
From the perspective of scholars like Miller and Neal, spirituality in the workplace or the Faith at Work movement function as a religious response to changes normally associated with neoliberal capitalism: globalization, deregulation, etc. For them, workplace spirituality represents a radical, perhaps even revolutionary, departure from conventional managerial norms that too often dehumanize and subordinate the lived experiences and interests of working people to the needs of the firm. Despite such claims, however, it remains a deeply neoliberal project. The emergence of workplace spirituality in American business thought during the late twentieth century coincides with the triumph of neoliberal political culture, embodied first in the election of Ronald Reagan to the United States presidency and later in Bill Clinton's embrace of 'free trade' and reform of the welfare state. Yet, this rise is more than mere coincidence. Rather, interest in spirituality at work can only be adequately explained as an extension of existing trends in management thought that contributed to this shift towards a neoliberal orientation. Indeed, workplace spirituality advances the neoliberal project, as outlined by its critics. As we shall see, it naturalizes the capitalist logic, indeed super-naturalizes it by reconfiguring it as a truly utopian project. The market is not merely a reflection of human nature; it is the echo of a divine order, and the telos of all human striving is to perfect the mundane expression of this celestial form.

\section{Radical Subject Formation}

Workplace spirituality is not merely neoliberal, it is a form of neoliberal governance in two ways. First, it is, and always has been, a managerial tool, a set of tactics and habituated practices intended to reduce sources of friction in production. Yet, workplace spirituality also engenders modes of self-governance; it serves as a technology of the self, a practical regimen aimed at inculcating within workers more than a set of habits, but a way of experiencing reality, a way of knowing and being in the world that places subjective experience above and beyond all else. In short, it produces the quintessential capitalist subject, a radically individualistic subject for whom reality is itself merely the results of individual choices about how it is to be experienced.

Foremost, regardless of claimed aspirations to empower individuals and allow them to be authentic at work, workplace spirituality is, and has been since its inception, a business management strategy, a particular way of framing management decisions in order to facilitate production. Champions of workplace spirituality frequently resist these claims by distinguishing between those who, on one hand, use spirituality as a way to increase profits and themselves who envision spirituality as an intrinsic good. Yet, in the same breath, they will often make the case that tending to the spiritual needs remains 'good for business.' Such concerns betray an awareness among advocates that 
workplace spirituality possesses a latent potential for exploitation. As easily as they express these concerns, they nonetheless resist seeing this potential in their own models.

Of course, treating spirituality as a means rather than an end doesn't necessarily imply exploitation. Workplaces can conceivably promote respectful culture for employees and therefore breed high levels of job satisfaction without taking undue advantage of their labor. However, in practice, workplace spirituality, like any other management strategy, is often mobilized in ways that undermine the interests of subordinates and bolsters managerial authority.

Workplace spirituality not only constitutes managerial strategy, but also a mode of subject formation. It quite literally holds the potential to reshape the individual. Managers use workplace spirituality as a way to approximate organizational interests as those of the employee, but it also takes hold at a much more fundamental level of social relations, reshaping not only individual perceptions about their interests but the basic epistemic mode of which the self is perpetually reproduced, reality is perceived, and consequently the horizon of possible action in the world. Individuals therefore acquire an ontological map and way of knowing compatible - perhaps identifiable - with a neoliberal social order. In short, they are (re)cast as neoliberal subjects.

Judi Neal acknowledges this relationship between subjectivity and workplace spirituality in her concept of the Edgewalker. She declares 'that a new kind of human being is emerging on the planet and that this has major implications for business, governments, religion, education, and all of our social institutions' (Neal 2006, p. xv). According to Neal, these 'edgewalkers,' who walk between this world and the spiritual realm, are autochthonous beings of exceptional abilities destined to lead humanity into a new paradigm. She characterizes them as the twenty-first-century iteration of the medicine men of 'ancient cultures' (p. 2). Edgewalkers represent 'the corporate shamans who walk into the invisible world and bring back wisdom and guidance for their organizations' (p. 10).

I agree with Neal's assessment that a new kind of individual is emerging, not as the charismatic herald of a new age but a rather ordinary type of subject suited to this new (i.e. neoliberal) age. The enactment of workplace spirituality - its practices and beliefs - is one way in which this subjectivity is sustained. In this way, it performs a pedagogical function, akin to Foucault's notion of a technology of the self. These technologies 'permit individuals to effect by their own means or with the help of other a certain number of operations on their own bodies and souls, thoughts, conduct, and way of being, so as to transform themselves in order to attain a certain state of happiness, purity, wisdom, perfection, or immortality' (Foucault 1988, p. 18). As Foucault states, these technologies of the self operate in tandem and in relation to other 
'matrices of practical reason,' including technologies of production, power, etc., the confluence of which enforces a particular set of social dynamics and structures. Unlike its role as a resource for strategic management of individuals by organizations, this dimension of workplace spirituality is not imposed by authority but taken up by employees themselves, in a nominally voluntary and often tacit manner. The application and habituation of this practical regimen results in a neoliberal subject suited to the local requirements demanded by sites of production (i.e. in workplaces) and for the maintenance of global capitalist social structures. If the previous section demonstrated workplace spirituality as a form of managerial governance, this section focuses on how it operates as a neoliberal governmentality, cultivated within subject.

I refer to this novel form of subjectivity as neoliberal precisely because it is constituted by what Doreen Massey labels 'vocabularies of the economy,' a neoliberal lexicon employed not only to 'talk about the economy in particular' but as a way of organizing life more generally (2013, p. 10). Massey characterizes the framework as an interpretive filter through which individuals 'are primarily consumers, whose essential duty (and source of power and pleasure) is to make choices' (p. 10). Certainly, the 'human-as-consumer' plays a crucial role in perpetuating neoliberal ideology, but more elementary is Massey's observation that these neoliberal vocabularies operate on and reinforce the assumption that 'individual interests are the only reality that matters; that those interests are purely monetary; and that so-called values are only a means of pursuing selfish ends by other means' (p. 10).

These vocabularies accomplish more than establishing selves as consumers, for they also cast individuals in their role as producers according to neoliberal logic. Whereas the modern liberal subject is perceived as a stable, autonomous, and rational actor in the political economy, the neoliberal subject is flexible, holistic, and intuitive. Rather than active, she remains reactive to ever shifting market forces. ${ }^{5}$ As Carla Freeman suggests, 'the self as an entrepreneurial "project" under constant renovation is a key signpost of neoliberalism and its perpetual quest for flexibility in the changing global marketplace' (Freeman 2014, p. 1). Similarly, the work of Dardot and Laval asserts that neoliberal subjects become 'enterprises' - agents competing in a social order organized around market principles - as the basic model for the self (Dardot and Laval [2009] 2017, p. 259). Moreover, Ulrich Brockling's scholarship specifically links the popularization of entrepreneurial modes of the self with late twentieth-century 'management literature' (Brockling 2016, p. 101). Taking this further, I want to suggest that the language of spirituality, as illustrated in workplace spirituality, has proven especially central to the fabrication of this new, flexible form of subjectivity. Indeed, even Brockling cannot help but employ concepts to describe this entrepreneurial self. 'Faith in the creative potential of the individual,' he declares, 'is the secular religion of the entrepre- 
neurial self' (p. 101). In the remainder of this chapter, I will explore in a more concrete manner how workplace spirituality facilitates the formation of radical subjects suited to our neoliberal moment.

\section{PARSING THE CASE: NEOLIBERAL SPIRITUALITY IN AMERICAN BUSINESS EDUCATION}

The neoliberal character of contemporary workplace spirituality appears most visibly with the emergence of the 'management, spirituality, and religion' (MSR) subfield in the Academy of Management, the largest professional society of scholars engaged in management research. Formed in the first years of the new millennium, MSR was the brainchild of a small band of academics who believed that conventional approaches to the study of management needed reform. Research, they asserted, relied too heavily on empirical, and in particular, quantitative methods, often overlooking the kind of 'person-centered' realities facing day-to-day managers. They founded MSR as a program unit within the academy as a way to promote generative research into the contributions that religious and spiritual perspectives might make to the existing body of knowledge. Over the years, MSR has situated itself as a kind of central hub, a clearing house for the latest perspectives on spirituality in the workplace.

Over the years, scholars pursuing research on workplace spirituality have formulated various founding mythologies to justify their shared identity. Typically, these mythic narratives explain workplace spirituality as an emergent movement within business aimed at transforming the nature of work specifically and society generally. The group often characterizes the movement as restorative, perhaps even redemptive. For them, the incorporation of spirituality into the workplace is not an innovation but rather a return to a more natural order, a rejection of the modern rationalization of society in favor of an imagined pre-modern arrangement when work and social relations were imbued with sacred meaning and purpose. Indeed, in the process of crafting this broader mythology, a handful of historical figures have emerged as 'founding fathers' of the movement whose scholarship provides the conceptual basis for much of the MSR research conducted to this day.

One such figure often touted as a pioneer of workplace spirituality is Willis Harman (1918-97), an electrical engineer who turned away from his profession to embrace futures research at the Stanford Research Institute during the second half of the twentieth century. Judi Neal, former director of the Tyson Center for Faith and Spirituality in the Workplace and co-founder of the MSR group, credits Harman as one of the earliest proponents of bringing spirituality into the workplace, but I want to suggest that a closer examination of his intellectual legacy demonstrates how workplace spirituality represents 
a comprehensive vision for the creation of a neoliberal social order and the formation of radical subjects.

While advocates of workplace spirituality see Harman's views as transformative, his thoughts mirror those of Drucker and the new generation of management philosophers. Industrial society, he maintains, suffers from an overly rationalized and fractured worldview that separates work, home, and worship, thereby denigrating the individual. Modernity, while it has produced unparalleled prosperity, has impoverished the individual by turning workers into factors of production deprived of, first, meaning, and eventually as a result of technological advances, jobs (Harman 1974, p. 9). Given this situation, Harman fervently believed that a radical shift in consciousness was required, one that would fundamentally reconfigure the role of work. In the future, he opined, only a fraction of the labor force would be engaged in actual work to meet the material needs of society, but nonetheless work would still serve as the source of self-worth. Under such conditions, 'employment is primarily the activity of self-development, and secondarily the production of goods and services' (Harman 1974, p. 9).

This new era of self-improvement would be defined by a reintegration of inspired forms of knowledge into the workplace. 'There are today,' he claimed, 'multifold signs of a respiritualization of Western society, with emphasis on self-realization, transcendent meaning, and inner growth leading to wisdom and compassion' (Harman 1988, p. 121). What he repeatedly refers to as the 'Perennial Wisdom' of the world's religious traditions will gain new epistemic authority, infusing each and every experience with profound meaning and purpose.

Harman tied this self-improvement ethic of work to a particular kind of social order, which in retrospect undeniably endorses neoliberal worldviews. It would be the business world, not nation-states, that would lead this shift in consciousness. 'The modern business corporation,' he wrote in 1988, 'is probably the most adaptive institution humankind has ever devised' (Harman 1988, p. 131). It would be the biggest private-sector actors-corporations - who should 'assume responsibility for the whole of society' (p. 131). In pursuing his program to reintegrate society, Harman would become an integral part of the burgeoning efforts to (re)introduce spirituality into American business. He spent the last decade of his life as director and co-founder of the World Business Academy, a liberal think-tank dedicated to facilitating this 'transindustrial age.' However, it is important to note that, as a futures researcher, Harman was not merely prescribing radical social reform, he saw his project foremost as descriptive, identifying trends already taking place. Discerning this sleight of hand remains crucial to understanding the neoliberal ideological work that Harman's philosophy performs. For him, business has already eclipsed the nation-state and social relations already only make sense in terms 
of the capitalist markets. The perfectibility of humankind will inevitably take shape only insofar as we acknowledge this paradigmatic fact.

Harman crafted a neoliberal mythology that he passed to his intellectual progeny like Judi Neal and others in the MSR universe. When Neal boldly declared at a conference in 2011 that 'business is the way we can transform consciousness precisely because it is so powerful today,' she is not merely restating platitudes often voiced by champions of the marketplace but, rather, affirming a key ideological aspiration of workplace spirituality: to remake the world in terms that can only be understood as neoliberal. This expressed goal of 'transforming consciousness' indicates that workplace spirituality targets more than societal reform; it has its sights aimed squarely on the formation of subjects themselves, and here Harman's intellectual project offers key insights into the mode of subjectivity it seeks to produce.

Harman begins from the assumption that the industrial society of the twentieth century, characterized by its 'direct measures' for dealing with the problems of poverty and inequality, has reached an impasse and is giving way to a new transindustrial paradigm. ${ }^{6}$ If the industrial era is characterized by attention to 'physical frontiers of geography and technology, in the transindustrial society concern would shift to the inner frontiers of mind and spirit,' he asserts (Harman 1979, p. 1). Accordingly, he suggests that his radical epistemological turn inward will reconfigure individual and society alike. 'It would assume the existence of a spiritual order, discoverable and explorable, and in some sense testable, against which human value choices could be assessed; emerging from this spirituality would be a creative work ethic, placing a high value on aware participation in both individual and social evolution' (pp. 2-3).

In linking this paradigmatic shift in human consciousness to an ethos of work, Harman is essentially offering a primer for the neoliberal subject. Drawing on the work of Aldous Huxley, he suggests that the principles of the 'perennial philosophy' will guide humanity in the coming age. Turning towards spiritual resources nurtures a 'higher awareness' that 'all knowledge and power is ultimately accessible to the mind looking within itself, and that all limitations are ultimately self-chosen' (Harman 1979, p. 105). Harman, again, links this new perspective to a novel attitude of work, that it will produce 'the desire to participate consciously, to labor and serve, in the evolutionary process, the fulfillment of mankind' (p. 105). Thus, the trajectory of this perceived shift, its ultimate end, is the production of a new type of worker whose impetus to work stems not from material needs but from a desire for the holistic spiritual advancement of society, a neoliberal society shorn of the trappings of the welfare state. He continues, 'But the reverse side of this attitude is acceptance, the choosing of what is, since at some deep level the self already chooses this' (p. 105). At this point, Harman appears to contradict himself in this final caveat. On one hand, the transindustrial subject must realize that 'all 
limitations are self-chosen,' but on the other, she must accept 'what is.' Yet, in reconciling this seeming incongruity, Harman offers a glimpse of what I refer to as the radical subjectivity engendered through the enactment of workplace spirituality.

In order to resolve this dichotomy, Harman suggests that the transindustrial human operates according to a particular ontology, or theory of reality: perception creates reality. In Global Mind Change (1998), he takes seriously the largely unsubstantiated claims of thinkers like Fritjof Capra, who suggested in his widely popular New Age book The Tao of Physics (1975), that quantum physics affirmed Taoist and Buddhist assertions that 'mind seemed to have some effect in the physical world' (Harman 1988, p. 13). The industrial age was marked by what Harman refers to as 'Materialistic Monism' where it is understood that 'matter gives rise to the mind,' whereas the transindustrial age is giving rise to 'Transcendental Monism in which the mind gives rise to matter' (Harman 1988, p. 35). The transindustrial age will presumably bring about an awareness that 'by deliberately changing the internal image of reality, people can change the world' (p. 157).

Harman proposes a radical subject sharply distinct from the modern liberal subject. The latter - the liberal conception of the subject-persists in a cartesian world in opposition to the objective world. The liberal self experiences reality out there through its particular subjective lens, and effects reality through its external activities. For the radical subject, however, the objective conditions collapse into subjective perception itself, rendering perception as the measure of what counts as the real. 'Mind or consciousness is primary and matter-energy arises in some sense out of mind,' he explains, and 'ultimately the reality behind the phenomenal world is contacted not through the physical senses, but through deep intuition' (Harman 1988, p. 34). The subject therefore becomes radical in the sense that its conquest of the object is complete, rendering the objective world out there as little more than a reverberating echo of one's conscious or unconscious choices made from within. The implication, then, is twofold. The radical subject is, at once, empowered to shape their perception of experience and compelled to accept these experiences not as the result of objective conditions but as the product of their own making.

Of course, as a futures researcher, Harman understands his project as predictive of trends already occurring, as one possible social order in the process of becoming. Indeed, in the context of his broader prediction for society, this radical subject appears just. As the industrial paradigm wanes, so does its unnatural predilection for unceasing economic growth, environmental destruction, and global competition for resources. Likewise, Harman treats the relatively equitable distribution of wealth and power between labor and capital that emerged after the Second World War as immutable. Under such hypothetical conditions, it is conceivable that individuals, having achieved relative 
material and economic security, could come to experience work as 'primarily for self-development,' as he suggests (Harman 1988, p. 146).

Yet, while his predictions for a transindustrial era have not come to fruition, his prescriptions for the integration of spirituality and work have been taken up, refined, and put into practice, not, as we shall briefly explore, as part of a larger shift towards a more just and equitable social order, but to uphold the very structures that sustain the very suffering Harman sought to defeat. Also, it is important to note that while not all proponents and practitioners of workplace spirituality have been directly influenced by Harman's work, his philosophy illustrates a general pattern for how workplace spirituality operates as a technology of the self. The engendering of radical subjectivities through workplace spirituality reshapes employees into willing participants in a neoliberal social order that, ironically, only diminishes their ability to choose their own reality.

Harman's ideas echo part of the wider discursive world of workplace spirituality among the MSR community and in business schools. Consider, for instance, how one MSR leader mobilizes these discourses within the framework of a business class to engender radical forms of subjectivity, equipping business elites with tools to navigate life under neoliberal conditions. The course, titled 'Spirituality for Business Leadership' and facilitated by the late Andre Delbecq, professor of management at Santa Clara University and long-time proponent of integrating spiritual perspectives into business education, introduces enrollees (MBA students and executives) to a diverse regimen of readings from 'the spirituality tradition.' As described by Delbecq (2000), the course culminated in a two-day retreat at Villa Holy Names, a retirement complex for Catholic nuns in the foothills of Santa Cruz in northern California. Delbecq describes the retreat as an opportunity to rehearse the teachings to which the students and executives had been exposed during the course.

The course itself clearly frames spiritual practice as a recipe for coping with and flourishing under the pressures of the marketplace. Delbecq, for example, depicts daily meditation as a way of 'listening to the inner voice in the midst of turbulent business environments' (Delbecq 2000, p. 119) and suggests that contemplation can mitigate the 'hectic space of a business leader's life' (p. 122). Yet the course also leverages spirituality as a pathway to reflect on broader socioeconomic concerns. It addresses Christian, Buddhist, and Taoist teachings on wealth and poverty and considers the obligations of the privileged for helping 'the destitute' (p. 121). However, Delbecq interrogates these issues with students through an overtly neoliberal lens by marking CEOs as 'wealth creators' and limiting discussion to solutions that uphold the principles of economic liberalism. Eschewing state-led efforts altogether, the course reduces social justice to the deeds of individual market-based actors. Focusing on 'almsgiving, justice giving, charity giving, philanthropy, stewardship' domes- 
ticates social justice for neoliberal capitalism by occluding the possibility of structural reform. Moreover, Delbecq redescribes 'poverty as a spiritual path,' which, like Harman, renders an objective socioeconomic position as a matter of perspective.

The retreat at the end of the course transmutes these ideas into embodied practice. Each morning begins with a 'mindful walk' followed by personal reflection on spiritual readings. At the end of the first day, Delbecq sends the attendees out to witness 'a place of suffering' that they 'most feared' (p. 122). Participants chose various sites - a center for disabled children, a homeless shelter, a hospice - for their field activities, but ultimately these experiences are only valued for their relevance to professional life with the intent of cultivating a malleable self capable of weathering the demands of the neoliberal workplace. Consider Delbecq's account of the debriefing on suffering following the field experiences:

Examples of suffering might include the selflessness required by the intensity of the leadership role with its demand on time, emotional energy, and absence of privacy; the inexorable criticism and backbiting directed toward leaders; the loneliness of the office and demands of confidentiality; the anxieties when addressing the new strategic challenges; the special burdens of bearing bad news in firings and layoffs; the humbling uncertainties when stepping down from high prestige roles; and so on. (p. 125)

Attendees therefore finish the retreat with admittedly powerful first-hand experiences of acute human suffering, but they acquire a perspective that erases the stark and substantial objective differences in suffering. Homelessness, acute physical disability, and terminal illness stand alongside 'the loneliness of the office,' the 'special burdens' of laying off employees, or the 'humbling uncertainties' of 'stepping down from high prestige roles.' The exercise casts suffering as a subjective experience to which everyone, even business elites, is subject, and ultimately finds resolution in the habituation of the proper mindset vis-à-vis spiritual practice. In the end, the 'Spirituality for Business Leadership' course accomplishes more than preparing business elites for the tumultuous and unpredictable marketplace; it exonerates the existing social structures from which they directly benefit.

\section{PARSING THE CASE: RADICAL SUBJECTS IN AN AMERICAN WORKPLACE}

While Delbecq and Harman certainly remain revered figures among business scholars of workplace spirituality, it is important not to overstate their broader significance. Indeed, the MSR community persists at the margins of management scholarship, evidenced by its ongoing failure to gain full recognition as a 
'division' in the Academy of Management, instead settling for the less prestigious label of 'interest group' since its inception in 2000. Courses like Delbecq's that teach spiritual perspectives on business remain scant and frequently are framed as experimental in nature, rarely if ever comprising part of the standard curriculum. The literature on workplace spirituality stands at the boundaries of the scholarly canon and, moreover, largely disconnected from the actual executives and managers practicing their craft in the American marketplace. It would therefore be grossly improper to claim that workplace spirituality, as an academic discourse, impacts the culture of American business in any substantial way. However, in the context of American business, there exists a growing, if still marginal, segment of organizations, business owners, and entrepreneurs who are putting these very ideas into practice and positioning spirituality as the hub of their workplace cultures, even if they remain wholly unaware of their counterparts in the management academy. As I have argued elsewhere, the genesis of interest in spirituality in the workplace can be observed from multiple vantage points - at the intellectual as well as the practical levels - and as emerging out of numerous cultural forces, including New Age religious perspectives, shifting popular attitudes and expectations about work, and seismic socioeconomic changes like globalization and post-industrial modes, particularly in the West. ${ }^{7}$ My point is that, while seemingly unrelated, scholarly interest in workplace spirituality and the integration of spirituality into business cultures are products of the same discursive environment and are therefore allies in the broader proliferation of neoliberal subjects.

The MSR community and courses like Delbecq's equip elite actors (in business and the academy) with subjectivities capable of thriving under a neoliberal order, whereas businesses that enact workplace spirituality promote distinct modes of radical subjectivity more suited to more vulnerable constituents (e.g. middle managers, working-class Americans). In the case that follows, we take a closer look at how one particular business mobilizes discourses on spirituality as part of its workplace culture in ways that reproduce neoliberal orthodoxies, reshape subjects, and, ultimately, protect or advance organizational interests.

Founded by Matthew and Terces Engelhart, Café Gratitude is a West Coast coffee chain that subscribes to a novel business philosophy known as 'Sacred Commerce.' The Engelharts have shaped the entirety of their business model around the conviction that business can be a 'path to spiritual awakening' (Engelhart and Engelhart 2008). They understand this exclusive brand of spirituality as a way of life and encourage their employees to enact its principles both inside and outside the workplace. Sacred Commerce, as practiced, represents an all-encompassing set of values and convictions that regulate all aspects of the enterprise, from large-scale strategic planning to day-to-day 
decision making and even the way employees interact with each other and with customers.

The Engelharts have even developed an array of employee training workshops that serve to instill the virtues of their business philosophy. As part of my research, I was permitted to participate in one such workshop called The Abounding River in the Spring of 2012. While employees are 'encouraged' to attend the workshop, they are not compelled and, for a not unsubstantial fee (at least for someone like myself surviving on a graduate stipend), members of the general public are welcome to attend.

Over the course of the two-day course, Abounding River helps individuals discover that 'abundance' is a state of mind, 'a quality of spirit, of the divine, a flavor' or human experience. Through a combination of lecture, discussion, and activities, the workshop challenges participants to reassess and transform their relationship to money in order to experience true fulfillment. As the Abounding River Logbook (given to participants) states, 'being abundance' requires 'living in the assurance of being supplied as a mindful practice to connect to Spirit in everything' (Engelhart and Engelhart 2007, p. 22).

The Engelharts present the workshop as a practical regimen for spiritual transformation, but it also accomplishes significant ideological, specifically neoliberal, work. The lessons, anecdotes, and activities each reinforce capitalist logic as the irreducible fabric of human society; fabric that American norms, according to the Engelharts, pervert. Money, for example, is characterized as the ultimate 'sacrament,' 'a body fluid that holds us all together,' and 'an expression of Spirit and Abundance flowing through us, connecting us all' (Engelhart and Engelhart 2007, p. 62). The more one spends, the more one impacts the lives of others. One's spending is another's paycheck, and the more we spend, the more we promote wellbeing and the social good. Consequently, institutions that hinder this sacred flow, namely regulatory apparatuses, are disrupting the spiritual and material lifeblood of humanity. 'When we hoard money,' Matthew told the class, 'we stifle life itself ... Keep the cycle of giving and receiving going - keep things in the flow.'

According to the Engelharts' two-dimensional map of reality, society is comprised of the sum total of market actors, and these actors are equal and ultimately responsible for their choices. Like more traditional defenses of free markets, the Engelharts understand suffering as a character flaw, rather than the result of unjust socioeconomic regimes. However, even when real forms of economic injustice appear undeniable, they suggest these are but illusions to be eliminated through the cultivation of the proper attitude. To justify this claim, they recounted to workshop participants the story of a homeless woman they had met. After repeated refusals of their help, the woman had explained to the Engelharts that living on the streets had been more of a blessing than a curse. 'She had lost weight at last, had more time to read, and had a great community 
of friends who share and look out for one another,' recalled Terces (Engelhart and Engelhart 2007, p. 60). Surprised by the optimism of the woman, the Engelharts had learned an important lesson, they declared: 'homelessness is just another way of life. It's not worse. It just looks different from my perspective. This woman was healthier than she'd ever been in her entire life,' she concluded.

In addition to crafting a neoliberal worldview, the case of Café Gratitude illuminates how spirituality in the workplace can become exploitative. The Engelharts remain ambivalent about the role of spirituality in Sacred Commerce. At times, they deny spirituality as a management strategy but as the end of their business itself. Their philosophy, Sacred Commerce, envisages business as 'a sacred container for the transformation of the participants, expressed as prosperity and abundance' (Engelhart and Engelhart 2008, p. 7) Rather than spirituality as a tool for improving the workplace, it is the workplace, run according to the principles of Sacred Commerce, that 'is going to birth a new community and a new human being' (p. 7).

Yet, my research into the culture of Café Gratitude reveals how Sacred Commerce operates in practice as a form of managerial power. In their book Sacred Commerce: Business as a Path to Spiritual Awakening (2008), the Engelharts write 'when we get attached to members of our staff or begin to treat members of our management team as if they were irreplaceable, it becomes easy to accommodate the wants and desires of a single personality at the expense of the entire business' (p. 10). Here, they make a dramatic course correction from their claim that Sacred Commerce is strictly a way for business to transform individuals and society. The interests of the business remain central, and concern for employee wellbeing should not undermine them. The Engelharts and their managers frequently mobilize their spiritual philosophy to justify this position, as illustrated in the following anecdote in their book:

One of our managers wanted to go to Hawaii but rather than come to our meeting and request time off, she bought a ticket and then presented it as 'I already have my ticket so I need to get time off.' We supported her in seeing that she not only diminished her experience of being supported and celebrated by her management team, but she diminished their experience of being people who would of course want her life to be great and would alter their schedules to make her trip happen. She created a prerequisite and then made her request because she did not trust us to grant it without it. (Engelhart and Engelhart 2008, p. 71)

In this excerpt, it is unclear and unlikely that the employee violated any company policy when she chose to purchase a ticket before asking for time off. After all, she could decide how to proceed if she were unable to secure the time off from work for the trip. Nonetheless, the Engelharts condemn her actions on the grounds that even presuming to make the purchase without their 
prior approval transgressed the principles of Sacred Commerce. They present her actions as a spiritual malady, as a result her experience and those of others is 'diminished.'

Sacred Commerce is similarly used to justify lower pay for employees by redescribing such criticisms as misguided perceptions. Individuals are simply 'creating being so justified in feeling underpaid and overworked right now' (Engelhart and Engelhart 2008, p. 96). To suggest that wages are low, working hours too long, or workload too demanding is to make a subjective claim. Sacred Commerce reformulates the objective conditions of employment into subjective (and therefore malleable) perspectives, a move we will more closely examine later in this chapter.

The extent to which these anecdotes reflect the culture of Sacred Commerce as practiced in Café Gratitude proved elusive in my research. The company strictly regulated the manner of my access to interview subjects. Their chief administrator (presumably at the behest of the owners) dictated which locations I could contact for recruitment. Moreover, the general managers instructed me to sit in their cafés, and they would send those employees willing to speak with me. Curiously, or perhaps not so curiously, all of the individuals that agreed to an interview were either shift managers (hourly) or assistant managers (salary). In short, not a single non-managerial employee shared their views with me, which raises more questions. Are managers simply more flexible to leave their duties and speak with me? Or does this suggest a more profound distrust of front-line employees by management, or a voluntary hesitation on the part of these individuals to express their views out of fear of retribution? Or, do these workers simply not care because they lack any investment beyond their daily shifts?

Unfortunately, these questions must inadequately be addressed, but, at times, my conversations with managers did reveal some clues. For instance, when I asked one manager about their training experience, they repeatedly stressed that required training was minimal and mostly on the job, but the workshops like Abounding River were 'always recommended, never required but recommended. The same,' she said, 'with the Landmark Forum.' The Landmark Forum is a company that offers a comprehensive array of self-improvement programming. It is a direct heir of the earlier Erhard Seminars Training, a widely popular seminar during the 1970s that was subject to criticism for its somewhat aggressive methods. One journalist describes the Landmark Forum as 'a trusted ally of companies — - big and small-looking to increase the "personal productivity of their employees"' (Curbed 2014). Café Gratitude, the manager explained, 'pays a fifty percent scholarship to attend the Forum' as supplemental training for employees who have the desire to attend. They neglected to mention, however, that Café Gratitude was in the midst of dealing with numerous complaints over their training policies related to the Forum. 
A few years earlier, the company came under public scrutiny when a former manager claimed that she was improperly demoted and subsequently fired for refusing to attend the supposedly voluntary Landmark seminar (Levin 2009). Eventually a number of employees came forward to disclose similar experiences, resulting in formal litigation. In fact six months after the completion of my brief fieldwork, Terces Engelhart announced in a social media post that Café Gratitude would be closing all of its northern California locations in the wake of the scandal (Engelhart 2011). Although I could not substantiate the details of the litigation, one local media source reported that 'the lawsuits in question stem from former Gratitude employees who left the restaurant with a bad taste in their mouths, so to speak. East Bay Express, a weekly newspaper based in Oakland, California, published a 2009 article that claimed, among other things, employees were fired for not attending Landmark Forum classes' (SFIST 2011).

Given the tempest into which I had waded, the manager's emphasis on the voluntary nature of the workshops comes as no surprise, but her further remarks on the matter prove equally illustrative of coercion in the practice of Sacred Commerce. Referring to the Café Gratitude workshops like Abounding River, she opined, 'It's kind of like why would you not go. It's free to you and you're here. So most people end up going to at least one or two of the workshops. And they're amazing.' After celebrating the classes, the manager makes one last telling observation. 'People who really take on the curriculum, and do the workbook, and go to the workshops, they are the ones who get so much out of working here. And people who stay on the periphery, they might have a more peripheral experience.' Although she saw the 'peripheral experience' of those who failed to embrace, learn from, and grow in extracurricular spiritual regimen, be it Landmark Forum or the various internal workshops, I couldn't help but wonder if this inverted the lived experience for many employees. Did the skills acquired in the workshops better prepare them for success in the company? Or was participation simply a gateway to advancement? It seems quite likely that these workshops serve as a veritable 'glass ceiling,' keeping the less compliant on the 'periphery' and therefore less of a threat to interests of the status quo.

In the end, one thing seems certain. Café Gratitude's owners, when disgruntled former employees threatened their material interests, chose to sell off their assets and cast their workers back into the labor market. Although I have no way of knowing if the Engelharts had any other viable option open to them, their rapid decision to close-something that just six months earlier seemed unthinkable to me during my fieldwork - appears at odds with their espoused commitment to the spiritual wellbeing of their workforce. Sacred Commerce purports to use business as a vehicle to transform others, but the telos of this transformation appears to be one of subservience to those who own the means 
of production, best captured in their own words: 'Like any initiate, the Sacred Commerce manager's life is a continuous act of surrender. The merchant priest lives in the paradox between emptiness, knowing nothing, and being a warrior of daring action. Their impossible promise to a transformed world is so extremely challenging and highly inspiring that their personal wants and habitual shadows have less sway over them' (Engelhart and Engelhart 2008, p. 50). Thus, Sacred Commerce constitutes a managerial strategy for enforcing organizational interests, but it potentially operates at a much deeper level, at the level of individual subjectivity, reminiscent of Delbecq's course on spirituality in business. Yet, if Delbecq's course inculcates a radical subjectivity through which business elites may prosper, the Sacred Commerce program at Café Gratitude represents one way that workplace spirituality inscribes similar modes of being for members of the working class but for very different ends. In this case, radical subjectivity serves as a psychic survival strategy for the powerless in society, who adopt a neoliberal vocabulary inside and outside of the workplace.

Each day when employees arrive and before leaving work at Café Gratitude, they practice a ritual known as 'Clearing.' In their Sacred Commerce, owners Matthew and Terces Engelhart state that 'Clearing is the foundation of Sacred Commerce' (2008, p. 25). The practice enlists a supervisor to 'clear' a subordinate as they begin and end their workdays (the Engelharts leave 'unclear' who 'clears' the ranking manager on duty). 'Clearing,' they explain, 'is a basic technique for distinguishing how the past is impacting the present and then presenting an opportunity to create something new and shift one's attention to something more empowering' (p. 25). The entire session may last just a few minutes or longer, depending on the needs of the one being cleared, and pursues two lines of inquiry asked in succession. First, the Clearer asks, 'what are you present to?' or some variation, to which their interlocutor responds. The second question aims to 'shift one's attention to something new; to be present now, to love one's life' (Engelhart and Engelhart 2008, p. 30). Once satisfied, the Clearer closes the exchange with an expression of gratitude for the person being cleared.

Superficially, the Clearing appears as nothing more than a way of getting focused for work and beginning one's shift with a show of respect. However, as a routinized practice, it holds the potential to reshape the way individuals perceive work and life. As part of my fieldwork at Café Gratitude, one of the general managers was eager to invite me to be cleared, giving me a unique opportunity to glimpse, in an embodied sense, the transformative potency carried across its performance.

Sitting on the patio together, having just finished lunch, the manager asked me, 'are you committed to being cleared today?' 
I agreed, and she closed her eyes for a moment of silence. Upon reopening her eyes, the manager stared intensely into mine, our gaze remaining fixated on each other for the duration of the Clearing.

Manager: First question: what's something you are afraid of being judged for?

In an effort to be authentic and not merely act 'as if' I were an employee, I confided in her my anxieties and feelings of insecurity related to completing the dissertation and attaining a $\mathrm{PhD}$.

Me: Being the product of state universities, I worry about whether I can live up to the high standards expected at an elite private school; I worry that my training and preparation have been inadequate, that I am just not smart enough to compete.

Already, I could feel my initial discomfort ease as I shared some of my most intimate fears with her.

Manager: So what I heard you say is you're fearful about whether you are good enough to be in graduate school. When you're present at that, when you're putting your attention on your fear of being judged, what are the emotions you're feeling when you're thinking about that?

Me: Anxiety, apprehension, that I don't want to do it, that I want to run from it.

Again, after repeating back my response verbatim, she says,

Manager: What do you think is underneath the anxiety? What are some of the emotions you might see?

I say, 'fear,' and she responds with gusto, 'Got it! Thanks for sharing that.'

Manager: Just take a few minutes and be there with that. That is a creation, right? When I'm putting my attention on being afraid of being judged for not being smart enough, I ... See that!?

Here, the manager has begun the process of reframing my negative fears as products of my own creation, as perceptions that I have chosen to put my attention on. Predictably, I start to feel a sense of detachment from these emotions; these fears, I think to myself, are not perceptions of the out there, but projections of my private insecurities onto the objective, neutral world. At this point she pivots to the second line of inquiry.

Manager: Now when you're ready, tell me what do your friends or people you know, what do they love about you? 
Me: That I am sincere, honest ... and that I am a good listener.

After announcing these affirmations about myself, my mood noticeably brightened. The Clearing had taken me through a process of exposing, detaching from, and rewriting deep-seated anxieties. As if I did not feel empowered already, she smiles and concludes, 'I want to acknowledge you for that. I want to acknowledge you for being committed to making a difference in the world, for impacting the quality of life on this planet through your work, and I also want to acknowledge you for being an amazing friend and for really caring about the people in your life.' The message couldn't be clearer. Simply by practicing a shift in how I perceived myself and the world, I was changing, even improving it. Moreover, as she explains, the clearing is not merely a conversational practice, 'it's actually an alchemical experience where the person getting cleared is getting to see. Where we put our attention is our experience. That's the basis of all of this ... Your experience has changed, not because we fixed the circumstances, but because you shifted your attention, which is like a magic trick of life.' Here, the picture of the radical subject manifests plainly; the source of suffering lies within subjective perception, not in the objective conditions.

Of course, I am not an employee of Café Gratitude and therefore my experiences can only approximate rather than recreate the quotidian experience of the Clearing among staff. The power dynamics between employer and employee have been replaced by a social interaction between myself, a novice field researcher, and my subject, a manager likely motivated to present their employer in an exemplary fashion. Surely, it is conceivable that some front-line workers merely tolerate the daily clearings as a part of the emotional and psychological labor demanded of their job.

Still, it is equally plausible that in subtle ways, the daily practice of learning to 'put one's attention' on the right perspectives becomes a basic way of organizing one's personhood. Consider, for instance, how one hourly shift manager with whom I spoke described the way Café Gratitude transformed her life. The employee, who self-identifies as of mixed 'white' and 'Native American' heritage, stated that she came to Café Gratitude at a pivotal time in her life. Upon returning from a trip to Peru after graduating from culinary school, she began 'thinking about how I don't want a job just to make money. What is more important to me,' she continued, 'is finding a place where I feel good. I can say what I feel, and I feel support from the managers. That's what I really started to put my attention on.' Finding Café Gratitude, she characterizes as her 'first spiritual manifestation of where I saw myself in the workplace.' The culture of Sacred Commerce, she explains, 'showed me how to look into myself and see what was the root problem.' As these remarks demonstrate, not only has 
this individual adopted the practice of shifting her focus inward to locate the source of suffering, she is actively redescribing her past prior to Café Gratitude through the language of Sacred Commerce (i.e. 'putting my attention on'). This suggests that these practices become central to both her ongoing identity work and her attempts to identify with the organization, each now inextricable from the other. This disposition obscures the objective social position that she occupies in the organization, subsuming her immediate interests to those of the employer and therefore establishing an opportunity for exploitation.

Nonetheless, despite the potential for abuse, the employees with whom I interacted appeared quite content in their jobs and convinced that these spiritual practices have positively transformed their lives. Consequently, to suggest that Sacred Commerce specifically, and workplace spirituality generally, only represents a form of managerial governance would misrepresent and devalue the sentiments of its practitioners. As a form of governmentality, as a technology of the self, however, it equally serves as a way for those subordinated to the structures of neoliberal capitalism to make sense of their worlds, and perhaps draw some measure of dignity from a social order fundamentally inflected to serve a global elite.

\section{CONCLUSION}

From a bird's eye view, workplace spirituality remains quite inconsequential to American business. As stated previously, the MSR group remains a marginal presence in the Academy of Management, having failed to attain full division status. And companies like Café Gratitude, which overtly associate their values and culture with spirituality, constitute an almost imperceptible niche within the juggernaut of the American economy. However, their relative insignificance obscures a more profound affinity with the trajectory of American corporate culture, providing insight into the way neoliberal ideologies inhabit our most personal dispositions. It is apparent in quite unexceptional business practices of corporate America. Mission and vision statements declare with moral authority the higher purpose of their goals, and it would be a rare find to discover any employer, whether in business, education, or even government, today that did not aspire to meaningful work and care for their employees.

At the individual level, these discourses penetrate, possess, and produce the expectations and dispositions of persons. And like radical subjects, we experience this turn towards a more humane workplace as human progress, even as the empirical reality suggests that our objective position in society has diminished. Working hours are longer, real wages are flat, and economic security is increasingly a fleeting hope for a dwindling American middle class. In writing this chapter, my most ardent hope has been to illustrate how workplace spirituality can be understood as a synecdoche for American corporate culture. 
If only because the integration of spirituality and work strikes the rest of us as exotic and starkly other, it sharpens our ability to perceive the often concealed and soft power relations that shape human labor under neoliberal capitalism. In its apparent abnormality, workplace spirituality reveals itself to be utterly conventional. After all, is there a substantial difference between practices labeled 'spiritual' and those dubbed 'mindful'? Is the rhetoric inscribed around 'core values,' 'guiding principles,' or 'mission statements' significantly distinct from 'spiritual wisdom' when either are deployed in the pursuit of profit? Can a project to use the marketplace as a medium to 'transform human consciousness' be anything but a neoliberal pursuit?

\section{NOTES}

1. The Journal of Management Inquiry, for example, dedicated an entire special issue in 2003 to research on workplace spirituality.

2. Faith-based employee resource groups mimic other employee affinity groups that first emerged in the mid-1970s as a way for employees from vulnerable underrepresented groups (i.e. African American, women, and LGBTQ+) to share their unique experiences and advocate on behalf of their particular interests in the context of their workplace. To date, I have not located any extant scholarly research into faith-based or interfaith employee networks specifically, although my preliminary findings suggest that these groups typically began to emerge during the late $1990 \mathrm{~s}$, coinciding with the rise of interest in spirituality in management thought.

3. For more specific information on corporate chaplaincy, see Miller et al. (2016).

4. Even more critical assessments, such as Hicks (2003) and Lambert III (2009), argue that spirituality in the workplace is driven by largely altruistic motives to render the workplace more humane.

5. The concept of the modern liberal self as an autonomous, inwardly stable, self-reliant rational agent has been articulated by a number of scholars in a wide-ranging number of disciplines. See Taylor (1989) for a thorough treatment tracing the intellectual history of the modern self, or Erik Erikson's numerous works in developmental psychology on the life cycle.

6. Harman (1979, pp. 21-2) condemns 'price and wage controls,' 'urban renewal programs,' 'welfare regulations,' 'minimum wage laws,' and 'programs dedicated to the reduction of inequalities of opportunity between the races' as ultimately counterproductive and indicative of the scientific materialism undergirding the industrial paradigm.

7. For a thorough treatment of how interest in workplace spirituality reflects deep cultural and structural shifts around economic production, see LoRusso (2017).

\section{REFERENCES}

Bourdieu, P. (1972), Outline of a Theory of Practice, trans. R. Nice (1977), New York: Cambridge University Press.

Brockling, U. (2016), The Entrepreneurial Self: Fabricating a New Type of Subject, London: Sage. 
Curbed (2014), 'Café Gratitude and the Cult of Commerce,' Curbed: Los Angeles, October 23.

Dardot, P. and C. Laval (2009), The Neoliberal Way of the World: On Neoliberal Society, trans. G. Elliot (2017), London: Verso.

Delbecq, A. (2000), 'Spirituality for Business Leadership: Reporting on a Pilot Course for MBAs and CEOs,' Journal of Management Inquiry, 9 (2), 117-28.

Engelhart, M. and T. Engelhart (2007), The Abounding River Personal Logbook: An Unfamiliar View of Being Abundance, Berkeley, CA: North Atlantic Books.

Engelhart, M. and T. Engelhart (2008), Sacred Commerce: Business as a Path to Spiritual Awakening, Berkeley, CA: North Atlantic Books.

Engelhart, T. (2011), 'To Our Café Gratitude Community,' Café Gratitude Facebook Page, November 29, accessed December 22, 2018 at www.facebook.com/permalink .php?story_fbid $=10150995099355074 \&$ id $=528890073$

Foucault, M. (1988), 'Technologies of the Self,' in L.H. Martin, H. Gutman, and P.H. Hutton (eds), Technologies of the Self: A Seminar with Michel Foucault, Cambridge, MA: University of Massachusetts Press, pp. 16-49.

Freeman, C. (2014), Entrepreneurial Selves: Neoliberal Respectability and the Making of the Caribbean Middle Class, Durham, NC: Duke University Press.

Garvey, M. (2018), 'Meditation Rooms Are the Hottest New Work Perk,' MarketWatch, October 26.

Harman, W. (1974), 'Humanistic Capitalism: An Alternative,' Journal of Humanistic Psychology, 14 (1), 5-32.

Harman, W. (1979), An Incomplete Guide to the Future, New York: W.W. Norton.

Harman, W. (1988), Global Mind Change: The New Age Revolution in the Way We Think, New York: Warner Books.

Harvey, D. (2005), A Brief History of Neoliberalism, New York: Oxford University Press.

Hicks, D. (2003), Religion in the Workplace: Pluralism, Spirituality, Leadership, New York: Cambridge University Press.

Holborow, M. (2015), Language and Neoliberalism, New York: Routledge Press.

Lambert III, L. (2009), Spirituality Inc.: Religion in the American Workplace, New York: New York University Press.

Lebowitz, S. (2016), 'I just spent a day in a mindfulness program developed at Google and left with 5 key lessons,' Business Insider, November 5.

Levin, S. (2009), 'I am annoyed and disappointed,' East Bay Express, August 5.

LoRusso, J. (2017), Spirituality, Corporate Culture, and American Business: The Neoliberal Ethic and the Spirit of Global Capital, New York: Bloomsbury Academic.

Massey, D. (2013), 'Vocabularies of the Economy,' Soundings: A Journal of Politics and Culture, 54, 9-22.

Miller, D. (2007), God at Work: The History and Promise of the Faith at Work Movement, New York: Oxford University Press.

Miller, D., F. Ngunjiri, and J. LoRusso (2016), 'HR Perceptions of Corporate Chaplains: Enhancing Positive Organizational Culture,' Journal of Management, Spirituality, and Religion, December, 196-215.

Neal, J. (2006), Edgewalkers: People and Organizations that Take Risks, Build Bridges, and Break New Ground, Westport, CT: Praeger.

Peck, J. (2010), Constructions of Neoliberal Reason, New York: Oxford University Press.

SFIST (2011), 'Café Gratitude Announces NorCal Closures,' SFIST, November 29. 
Taylor, C. (1989), Sources of the Self: The Making of Modern Identity, Cambridge: Cambridge University Press. 